ORIGINAL ARTICLE

\title{
Non-attachment and happiness: mediating versus moderating roles of grit personality
}

\author{
Poh Chua Siah (DD $A, B, C, D, E, F$, Pei Yin Tung ${ }^{A, B, C, F}$, Mun Ping Chan ${ }^{A, B, C, F}$ \\ Universiti Tunku Abdul Rahman, Kampar Campus, Perak, Malaysia
}

BACKGROUND

Studies have revealed that grit personality and non-attachment are positively associated with happiness. Grittier people are happier while they persist in pursuing their long-term goal, whereas non-attached people are happier as they are not clinging onto any object. These contrasting findings seem to suggest that the two concepts may have some relevancies. Accordingly, this study aims to use the mediator and moderator models to examine whether grit personality either moderates or mediates the effects of non-attachment on happiness.

\section{PARTICIPANTS AND PROCEDURE}

Three hundred sixty undergraduates were recruited by the purposive sampling method to participate in a survey. They needed to fill in the Short Grit Scale, Non-Attachment Scale and Subjective Happiness Scale.

\section{RESULTS}

The results showed that non-attachment is positively associated with a component of grit; that only perseverance of efforts, but not consistency of interest, was positively associated with non-attachment. In addition, perseverance of efforts mediates rather than moderates the effects of non-attachment on happiness.

\section{CONCLUSIONS}

The findings suggesting that non-attached people are happier does not mean they detach from life. They are able to work with perseverance on their long-term goals, but they do not attach to the outcome of their goals. The findings provide further conceptual clarification of grit personality and non-attachment and further information to educators and program managers while designing programs to improve happiness.

KEY WORDS

girt; non-attachment; happiness; mediator; moderator

Corresponding Author - Poh Chua Siah, Ph.D., Universiti Tunku Abdul Rahman, Kampar Campus, Jalan Universiti, Bandar Barat, 31900 Perak, Malaysia, e-mail: siahpc@utar.edu.my

AUthors' CONTRIBUtion - A: Study design - B: Data collection - C: Statistical analysis - D: Data interpretation .

E: Manuscript preparation · F: Literature search · G: Funds collection

to Cite this ARTICLE - Siah, P. C., Tung, P. Y., \& Chan, M. P. (2020). Non-attachment and happiness: mediating versus

moderating roles of grit personality. Current Issues in Personality Psychology, 8(1), 31-40.

RECEIVED 12.09.2019 • REVIEWED 25.02.2020 • ACCEPTED 26.02.2020 • PUBLISHED 30.03.2020 


\section{BACKGROUND}

Non-attachment is a flexible and balanced way of relating to one's experiences without clinging to or suppressing them (Sahdra, Ciarrochi, Parker, Marshall, \& Heaven, 2015; Sahdra, Shaver, \& Brown, 2010; Sahdra \& Shaver, 2013). In other words, non-attachment is a principle where one accepts both pleasure and suffering equally, or not being too involved or concerned about objects that bring pleasure and suffering (Pande \& Tewari, 2011). Studies have shown that non-attachment is the door to genuine happiness (Banth \& Talwar, 2012).

Based on this view, grittier people should be less happy as they have passion and perseverance to accomplish their long-term goals. However, Khan and Khan (2017) claim that grittier people should be satisfied or happy; otherwise they would not be working consistently to attain their long-term goal. If those people who are high in grit and in non-attachment are happy, it may indicate some conceptual similarity and relevancy between non-attachment and grit.

One possible explanation for the similarity is that the effect of grit on happiness is either mediated or moderated by non-attachment. In other words, even though grittier people persist towards their long-term goals, they have a clear idea and meaning for their goal to work on, and thus are less attached to the outcomes and feel happy. Accordingly, this study aims to examine the relationships between grit and non-attachment with respect to happiness, and whether non-attachment serves as a mediator or moderator for the effect of grit on happiness. In the theoretical contribution, the findings would provide more conceptual clarification of grit personality and non-attachment. In the practical contribution, the findings would provide information to educators and program managers while designing programs to improve the grit level of students.

\section{LITERATURE REVIEW}

Buddhism refers to a collection of philosophical, psychological, ethical, religious, and cultural traditions that came about as a response to suffering (Kelly, 2008). Within Buddhism, life is considered unsatisfying as it contains all types of suffering, and all pleasurable experiences are impermanent (Chen, 2006). Attachment or āsakti is the root of suffering, as being "attached" to one's beliefs, sensations, physical objects, other people, and even to life itself, indicates one's mistaken view of reality as fixed or permanent (Sahdra, Ciarrochi, \& Parker, 2016).

Therefore, different types of attachment, such as attachment to internal experiences, views about the self, other people and physical possessions, are regarded as the key determinant of dukkha or the fun- damental dissatisfactory nature of the human condition (Fischer-Schreiber, Ehrhard, Friedrichs, \& Diener, 1994). The dissatisfactory nature is stronger especially when the attachment is expressed through excessive desire, craving, grasping, or avoidance (Sahdra et al., 2016). When one is craving for a particular object or circumstance to feel secure, people will feel insecure, anxious, or empty when they lose that particular object or circumstance (Sahdra et al., 2010).

Accordingly, a way of reducing suffering is to eliminate craving and aversion through non-attachment, which is defined as a flexible, balanced way of relating to one's experiences without clinging to or suppressing them (Sahdra et al., 2015; Sahdra et al., 2010). In other words, non-attachment is a principle where one accepts both pleasure and suffering equally, or not being too involved or concerned about objects that bring pleasure and suffering (Pande \& Tewari, 2011). Non-attachment also means the disconnection of one's consciousness from unnecessary worries for the act that is related to the outcome, so that one can free oneself of desires, fears, hopes and attachments by means of living in the present, the moment (Pande, 2013). Through non-attachment, people are able to release from unhelpful fixations, especially to positive ideas about life, experiences and comparisons (Sahdra et al., 2010).

It is easier to confuse the concept of non-attachment with the concept of attachment that was proposed by Bowlby and Ainsworth. According to the review conducted by Peluso et al. (2004), attachment theory was proposed by John Bowlby in the 1950s and 1960s, and he proposed that a good attachment between an infant and the mother would provide a protective function in times of potential danger. It would also provide a secure base from which the infant is able to explore an environment. This theory has not been supported by the experiments conducted by Ainsworth and her associates but has also been extended and categorized into three types of attachment relationships, which are secure, anxiousavoidant, and anxious-resistant. Disorganized type of attachment is later included after culture and social context is considered. This is because a disorganized attachment was commonly found in the samples of low socioeconomic status (Sahdra et al., 2010).

The types of primary attachment between the infant and the mother have been generalized and have been known to affect the future development of an infant, such as future interaction with others, their broad social networks, and happiness (Bretherton, 1992; Gillath, Karantzas, \& Lee, 2019; Peluso, Peluso, White, \& Kern, 2004; Webster, 1998). Three types of adult attachment patterns have been found to be associated with their types of primary attachment, which can be categorized into three types of parents: autonomous-secure, preoccupied, and dismissing parents (Bretherton, 1992). In addition, secure and 
insecure attachments would have a different sense of closeness to the extent of their network members (Gillath et al., 2019). Moreover, secure and insecure attachments have also been found to be associated with positive and negative reminiscence among the elderly and thus affect their happiness (Webster, 1998). Trinh and Khanh (2019) claim that the associations between mutual relationships with happiness are more important in Asian culture. By using qualitative analysis of open-ended questions, they interviewed 58 participants in Vietnam and found the significant contribution of family and social relationships with their happiness.

By comparing the concepts of attachment and non-attachment, Sahdra and Shaver (2013) point out that non-attachment is similar to secure attachment as both concepts emphasized loving and supportive social relationships and the importance of reducing clinginess and aloofness. However, non-attachment's emphasis on the "subjective quality of ease and balance, not feeling 'trapped' or dissatisfied, not being stuck or fixated on mental representations" (Sahdra \& Shaver, 2013, p. 287), is different from the concept of attachment that emphasized external security, such as relationships, careers, wealth, or reputation.

Accordingly, non-attachment does not mean detachment from life, as non-attachment within Buddhism is not asceticism or detachment from others or society. It is more of a prerequisite for genuine caring and concern for others and the action needed to reduce suffering in the world (Berzin, 1988). Also, non-attachment does not mean that one cannot have values, needs or aims, and cannot act consistently in a devoted relationship like marriage. What is more important in non-attachment is that one is not dependent on a psychological aspect in any circumstances or results, and just accepts the flow, the way it is in life (Agrawal \& Jaiswal, 2013).

Non-attachment has been shown to be inversely related to dissociative tendencies, and positively related to dispositional empathy and generosity in adults (Sahdra et al., 2010). In addition, non-attachment was found to be negatively associated with burnout among accredited social health activist workers and produced a significant effect on job satisfaction. This is evident in the employees of International Automobile Organizations who have higher non-attachment levels and tend to have higher chances of developing good personality skills, which makes them feel more capable, social, satisfied, and accountable for all tasks at work (Pandey \& Singh, 2015; Upadhyay \& Vashishtha, 2014). Moreover, non-attachment was found to be a moderator for the relationship between distress and coping, where the higher the belief of non-attachment, the better the coping capability and thus lower level of distress (Pande \& Tewari, 2011).

Additionally, non-attached people have been found to be better at managing time, handling social situations and achieving important goals, as they are able to face challenges with a sense of calm and mental balance (Sahdra et al., 2016). Therefore, Banth and Talwar (2012) believed that non-attachment was significantly and positively associated with subjective, psychological well-being and happiness.

Recently, Whitehead et al. (2019) examined the relations of non-attachment with three psychological concepts (mindfulness, self-actualization, self-transcendence) and a Buddhist construct of wisdom. They found that non-attachment is positively associated with self-actualization and self-transcendence, and non-attachment mediates the effects of mindfulness on the three outcomes. Elphinstone and Whitehead (2019) also conducted a study to examine the relations of non-attachment with four psychological concepts: self-esteem, public self-consciousness, relative deprivation, and materialism. They found that nonattachment is positively associated with self-esteem but negatively associated with the other three factors.

Relative to non-attachment, grit is defined as passion and perseverance to accomplish a long-term goal (Duckworth, Peterson, Matthews, \& Kelly, 2007). Since grittier people do not give up easily and are willing to face and tackle obstacles or problems, they are more likely to achieve their long-term goals (Duckworth et al., 2007). Grit has two facets, which are perseverance of effort and consistency of passion for long-term goals. Perseverance is defined as staying on the same course of action, having no intention of changing focus, facing obstacles along the way, and finding pleasure in finishing tasks (Park, Peterson, \& Seligman, 2004). The meaning of perseverance transcends more than just mere self-control, as the meaning of grit has an emphasis on long-term stamina rather than short-term intensity (Duckworth et al., 2007). Consistency indicates a strong desire towards an activity that defines oneself, that one enjoys, loves or finds important, and in which one invests time and energy in daily (Vallerand, 2012).

It is believed that grit is more likely to be influenced by nature than nurture, since twin analyses showed that grit is moderately heritable and can be explained by genetic factors, with a heritability estimate of $37 \%$ for grit perseverance and $20 \%$ for grit consistency of interest. It is, therefore, argued that grit is considered to be very difficult to change (Rimfeld, Kovas, Dale, \& Plomin, 2016). However, grit increases with age and becomes greater when individuals understand lifelong goals, as well as their interests (Duckworth \& Eskreis-Winkler, 2013).

Also, grit is not relevant to one's intelligence, as grittier people tend to achieve more compared to people with a lower grit level even when they have the same intelligence quotient level (Duckworth et al., 2007). Grit is also different from self-control, where a grittier person will persist with their goal for months, years or even decades until they accom- 
plish their goal, whereas individuals with higher selfcontrol do not behave so (Duckworth \& Gross, 2014).

Khan and Khan (2017) challenged the concept that people who are regularly working towards their goals for a long period of time stay motivated, satisfied and happy; because if these people were not satisfied or happy, they would not be working consistently to attain their long-term goal. A study that examined the relationship between grit and happiness among professionals also showed that individuals with high grit levels are satisfied with their life (Khan \& Khan, 2017). Even though gritty individuals also view negative events as painfully as others, they may be more likely to maintain or alter their course instead of aborting goal-related efforts (Kleiman, Adams, Kashdan, \& Riskind, 2013). Culin, Tsukayama, and Duckworth (2014) further examined this issue and found that grit is positively correlated with engagement and meaning, but inversely correlated with pleasure. In addition, both perseverance and consistency of efforts are positively related to engagement and meaning, but only consistency of efforts is inversely correlated with pleasure. In other words, grittier people are happier if they do not seek pleasure from their goals.

\section{THE PRESENT STUDY}

Studies revealed that non-attached people are happier as they do not attach to the outcomes (Agrawal \& Jaiswal, 2013), and gritty people are happier as they found the meaning of engaging in their long-term goals (Culin et al., 2014). These similar findings seem to suggest that the two concepts may have some relevancies and that non-attached people can be gritty.

In addition, the moderator and mediator models in personality research that were proposed by Chaplin (2007) suggested that grit may either serve as a moderator or mediator for the effects of non-attachment on happiness. The moderator model is more relevant to the essentialist's perspective on personality, which claims that personality is a genetic trait that is stable and difficult to change, and thus the moderator model concerns the interaction effects of different personalities on certain outcomes. In other words, both the grit and non-attachment personality can only interact with each other to affect their happiness.

The mediator model is more relevant to the contextualist's perspective on personality, which claims that personality is a state that is possible to change due to the rapid physical, cognitive, and social changes, so it is assumed that a change of a certain state may bring the change of another state and causes certain outcomes (Caspi, Roberts, \& Shiner, 2005; Chaplin, 2007; Specht, Egloff, \& Schmukle, 2011). In other words, the mediator model is concerned about the issue that people with higher non-attachment may change their grit level and become happier.
Accordingly, two different hypotheses are created based on the expectations of the moderator and mediator models (Chaplin, 2007). Based on the moderator model, it is expected that non-attached people are happier, depending on their grit levels. However, based on the mediator model, because non-attached people are less concerned about the outcomes, they are more likely to enjoy the process of working on their long-term goal, and thus they are happier.

Therefore, the hypotheses of this study are as follows:

H1. Grit is positively associated with happiness.

$\mathrm{H} 2$. Non-attachment is positively associated with happiness.

H3. Non-attachment is positively associated with grit.

H4. Grit is the statistical mediator for the effect of non-attachment on happiness.

H5. Grit is the statistical moderator for the effect of non-attachment on happiness.

\section{PARTICIPANTS AND PROCEDURE}

\section{PARTICIPANTS}

Three hundred seventy-seven undergraduate students were recruited. This sample size is larger than the sample size suggested by Hair et al. (2016), who stated that the minimum sample size should be equal to the larger of ten times the largest number of formative indicators used to measure one construct, which is 80 . The number of valid questionnaires is 360 , as 17 set of questionnaires were uncompleted, so the response rate is $95.4 \%$. $48.3 \%(n=174)$ were male and $50.8 \%(n=183)$ were female and $0.8 \%(n=3)$ did not state their gender. The age of the participants ranged from 19 to $27(M=21.99, S D=1.43)$.

\section{PROCEDURE}

Purposive sampling used to select participants only recruited undergraduates. Participants were recruited from different classes, the library, and the university café. On the cover page of the questionnaire, information about the participants' right to not participate and the confidentiality of data they declared was provided. Participants were approached and then briefed about the purposes of the study, the confidentiality of the responses they provide, and their approval was requested to fill out a questionnaire that took approximately 10 to 15 minutes to complete. Once the participants had completed the questionnaire, the researchers thanked the participants for their cooperation. Four hundred questionnaires were distributed and 377 were collected, so the response rate was $94.25 \%$. 


\section{MEASURES}

Short Grit Scale (Grit-S). This scale consists of eight items and it uses a 5-point Likert scale ranging from 1 (not like me at all) to 5 (very much like me) for participants to choose from. A higher score indicates the item describes participants better. Four items (1, 3, 5 and 6) measure the consistency of interest and another four items (2, 4, 7 and 8) measure perseverance of effort. The internal consistency for this scale is from .73 to .83 (Duckworth \& Quinn, 2009). The higher the score, the grittier the person.

Non-Attachment Scale - Short Form (NAS-SF). NAS-SF consists of eight items and it uses a 6-point Likert scale ranging from 1 (disagree strongly) to 6 (agree strongly) for participants to choose from (Sahdra et al., 2010). A higher score indicates that participants agreed more with the item. NAS-SF was reported as reliable with Cronbach's $\alpha$ of .91. A higher total score indicates a higher non-attachment level (Chio, Lai, \& Mak, 2018).

Subjective Happiness Scale (SHS). The Subjective Happiness Scale consists of four items. Participants needed to rate the items using a 7-point Likert scale indicating the item that describes participants better - 1 (not at all) to 7 (a great deal). Cronbach's $\alpha$ ranged from .79 to .94 (Lyubomirsky \& Lepper, 1999). The higher the score, the happier the participants.

\section{DATA ANALYSIS}

After collecting the questionnaires, the data were keyed into an Excel file. Partial Least Squares Path Modeling was used for data analyses by the SmartPLS program (version 3).

\section{RESULTS}

\section{MEASUREMENT MODEL}

Construct reliability. The composite reliability of all parenting measurements ranged from .75 to .87 and their average variance extracted ranged from .51 to .62 (Table 1). Both results exceed the recommended value of .70 for the composite reliability and the recommended value of .50 for the average variance extracted (Hair et al., 2016). Correspondingly, the findings suggested that the latent constructs of all measurements are acceptable.

Discriminant validity. The heterotrait-monotrait ratio was used to examine the discriminant validity of the measurements and all results are below the critical values of .85 (Henseler, Ringle, \& Sarstedt, 2015) (see Table 2).

Coefficient of determination, effect size and collinearity statistics of measurements. The results of the analyses are shown in Table 3 . The variance inflation factor of all scales was below 5 (Hadi, Abdullah, \& Sentosa, 2016), which indicates that no collinearity issue was found. In addition, the results also reveal a large size effect of the predictors on happiness.

\section{STRUCTURAL MODEL}

As shown in Table 4, non-attachment is associated with happiness and perseverance, $p<.001$, and those who are high in perseverance have a level of happiness, $p=.715$.

Mediating effect. As shown in Table 4 and Figure 1, the specific indirect effect of non-attachment on hap-

Table 1

Construct reliability and validity of all measurements

\begin{tabular}{lccc}
\hline Factors & Item no. & Composite reliability & $\begin{array}{c}\text { Average variance } \\
\text { extracted }\end{array}$ \\
\hline Non-attachment & 7 (1 item removed) & 0.87 & 0.50 \\
Happiness & 4 & 0.86 & 0.62 \\
Consistency & 4 & 0.81 & 0.51 \\
Perseverance & $3(1$ item removed $)$ & 0.75 & 0.51 \\
\hline
\end{tabular}

Table 2

Discriminate validity of the three measurements

\begin{tabular}{lccc}
\hline & Consistency & Happiness & Non-attachment \\
\hline Happiness & 0.21 & & \\
Non-attachment & 0.22 & 0.60 & 0.51 \\
Perseverance & 0.49 & 0.45 & \\
\hline Note. All results are below the critical values of 0.85, under discriminate validity.
\end{tabular}


Table 3

Coefficient of determination $\left(R^{2}\right)$, effect size $\left(f^{2}\right)$ and collinearity statistics (VIF) of measurements

\begin{tabular}{|c|c|c|c|c|}
\hline DV & Predictors & $R^{2}$ & $f^{2}$ & VIF \\
\hline \multirow[t]{4}{*}{ Happiness } & & .27 & & \\
\hline & Consistency & & .01 & 1.11 \\
\hline & Perseverance & & .02 & 1.29 \\
\hline & Non-attachment & & .22 & 1.21 \\
\hline
\end{tabular}

Table 4

Results of the structural equation modelling

\begin{tabular}{lccccc}
\hline & Hypothesis & $\beta$ & $S E$ & $t$ & $p$ \\
\hline Perseverance $\rightarrow$ Happiness & $\mathrm{H} 1$ & .13 & .06 & 2.14 & .033 \\
Consistency $\rightarrow$ Happiness & $\mathrm{H} 1$ & .02 & .06 & 0.37 & .715 \\
Non-attachment $\rightarrow$ Happiness & $\mathrm{H} 2$ & .45 & .05 & 8.61 & $<.001$ \\
Non-attachment $\rightarrow$ Perseverance & $\mathrm{H} 3$ & .42 & .05 & 9.15 & $<.001$ \\
Non-attachment $\rightarrow$ Consistency & $\mathrm{H} 3$ & .17 & .17 & 0.17 & .166 \\
Mediating effect & & & & & .037 \\
Non-attachment $\rightarrow$ Perseverance $\rightarrow$ Happiness & $\mathrm{H} 4$ & .05 & .03 & 2.09 & .741 \\
Non-attachment $\rightarrow$ Consistency $\rightarrow$ Happiness & $\mathrm{H} 4$ & .01 & .01 & 0.33 & .725 \\
Moderating effect & & & & & .948 \\
Non-attachment $\times$ Perseverance & $\mathrm{H}$ & -.08 & .05 & 1.54 \\
$\quad$ Non-attachment $\times$ Consistency & $\mathrm{H} 5$ & -.01 & .06 & 0.07 & .948 \\
\hline
\end{tabular}

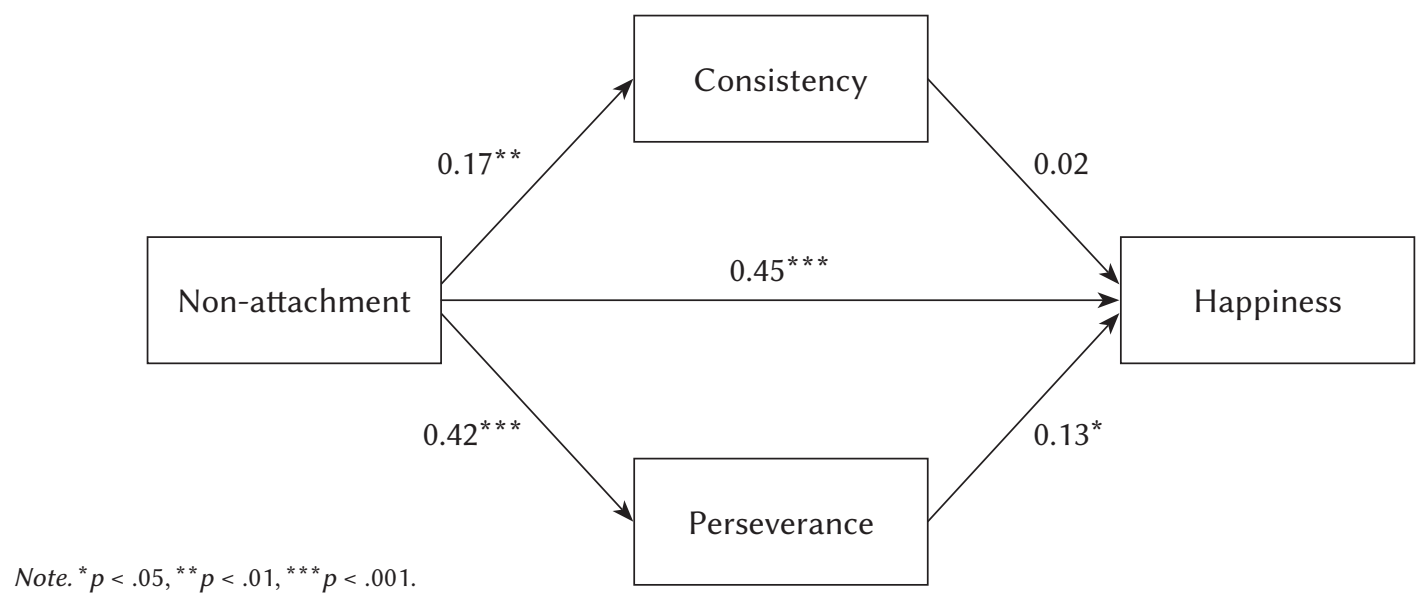

Figure 1. Mediating effects of grit on the relationship between non-attachment and happiness.

piness through perseverance is significant, $p=.037$, which indicated a mediating effect. In addition, the direct effect is also significant and the total effect is positive, which indicates a complementary mediating effect (Zhao, Lynch, \& Chen, 2010). However, the specific indirect effect of non-attachment on happiness through consistency is not significant, $p=.741$, which indicates that no statistical mediating effect was found.

Moderating effect. The SmartPLS program was run again to examine whether non-attachment moderates the effects of consistency of interest and perseverance of effort on happiness. The results indicate that the interaction effect between non-attachment 


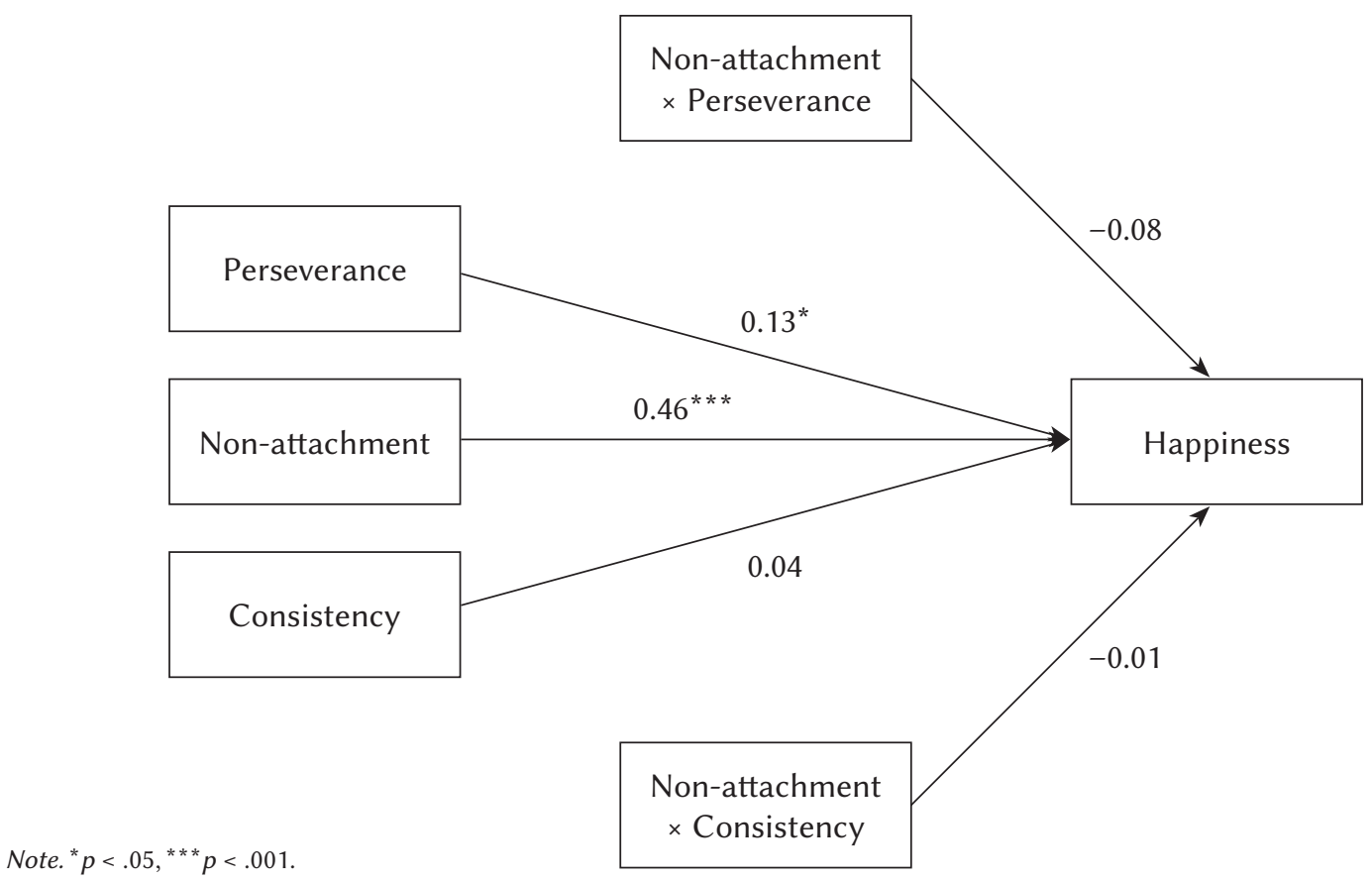

Figure 2. Moderating effects of grit and non-attachment on happiness.

and consistency of interest on happiness, and the interaction effect between non-attachment and perseverance of effort on happiness, are both insignificant, $p>.05$, which indicates no significant moderating effect emerged (Table 4 and Figure 2).

\section{DISCUSSION}

Studies found that people who are craving or attached to a particular object are less happier than those who are not, as people who are attached to objects are more likely to suffer from the possible loss of that object (Banth \& Talwar, 2012; Sahdra et al., 2010). Studies also found that grittier people who are able to preserve their effort to work on their long-term goals are also happy (Culin et al., 2014). These two similar findings that reveal the positive associations between grit and non-attachment with respect to happiness may indicate some conceptual similarity. Accordingly, this study predicts positive associations between non-attachment, grit, and happiness. In addition, by using the moderator and mediator models, this study further examines the relationships among the two personalities and happiness by asking whether the effects of non-attachment on happiness are either mediated or moderated by grit.

\section{NON-ATTACHMENT, GRIT, AND HAPPINESS}

The results support the relationship between nonattachment and happiness in which non-attachment is found to be positively associated with happiness. These findings are consistent with some results that show that non-attachment is positively associated with orientations to happiness, and also the views of the Indian tradition that happiness is related to desiring less and unaffected by either pain or pleasure (Banth \& Talwar, 2012; Nagar, 2018). However, the results only partially support the relationship between non-attachment and grit in which non-attachment is only positively associated with the perseverance of effort but not the consistency of interest, and also partially support the relationship between grit and happiness in which only perseverance of effort is positively associated with happiness. In other words, only perseverance of effort but not the consistency of interest is associated with happiness and non-attachment.

The different associations found in the two components of grit personality with happiness may be relevant to their different motivations. Perseverance of effort is found to be positively associated with pursuing engagement whereas consistency of interest is negatively associated with pursuing pleasure (Culin et al., 2014). A study conducted by Disabato, Goodman, and Kashdan (2018) revealed that perseverance of interest is positively associated with well-being but consistency of interest is negatively associated with well-being, and they explain that to keep feeling passionate about the long-term goal can be difficult to maintain their happiness. Similar results were reported by Datu, Valdez, and King (2016) in which perseverance of effort is positively associated with 
life satisfaction and positive affect, and consistency of interest is not relevant to well-being.

The different associations found in the two components of grit personality with non-attachment may also be relevant to their different motivations. As the consistency of interest is relevant to passion, passionate individuals are more likely to experience the difficulty of letting go or not clinging to the outcomes. Therefore, they are more likely to be affected by the setback or success they encounter during the process of pursuing their long-term goals (Kleiman et al., 2013; Sahdra et al., 2016). These feelings are less relevant to the concept of non-attachment. However, the positive association between the perseverance of effort and non-attachment indicates that nonattached people did have important goals, as it was suggested by Agrawal and Jaiswal (2013) that nonattached people did have desires, values or goals, and were able to behave consistently.

\section{MEDIATOR OR MODERATOR}

Using structural equation modeling, the results further showed that perseverance is a statistical mediator rather than a statistical moderator for the effect of non-attachment on happiness. In other words, individuals who are less attached to the outcomes of their tasks are more likely to feel happy in the process of working on their long-term goals. Some studies have also supported the contextualist views on grit personality that grit can be changed through the social context (Siah et al., 2019; Siah, Ong, Ngiam, \& Tan, 2018).

\section{CONCLUSIONS}

In conclusion, the findings of this study support the conceptual similarity between non-attachment and grit personality, that non-attachment does not mean detachment from life. Non-attached people do have goals and are able to persist in achieving their longterm goals, but they do not attach to the outcomes and thus they are happier. In addition, the findings also support the mediator instead of the moderator model of grit personality for the effects of non-attachment on happiness, which may imply that the improvement in non-attachment would improve an individual's perseverance of effort towards their long-term goals, increasing their happiness. These findings are important in terms of the practical contribution, as the results indicate that through the learning and development of non-attachment, one can improve an individual's grit level, and such improvement will lead to happiness. These findings are consistent with some studies that examine the possible change of personality through interventions to create various positive psychological effects (Roberts et al., 2017; Sedlmeier, Losse, \& Quasten, 2018).

Nonetheless, the interpretation of the findings needs to be cautious and not over-generalized. Since this sample of the study is recruited from undergraduates from a university, the findings may not be generalizable to other age groups and also undergraduates from other universities. Future studies may be required to repeat the study to examine the robustness of the findings. In addition, this study used a cross-sectional survey method to examine relationships. Future studies may consider using an intervention study with an experimental approach to provide a clearer cause-and-effect explanation. Moreover, more studies can be conducted to determine the relationships between non-attachment and some psychological constructs so that a better term of non-attachment can be proposed since the term of non-attachment may be easier to get confused with the psychological term of attachment.

\section{RefERENCES}

Agrawal, S., \& Jaiswal, S. (2013). Anasakti: Stress and coping in old age. Indian Journal of Gerontology, 27, 665-673.

Banth, S., \& Talwar, C. (2012). Anasakti, the Hindu ideal, and its relationship to well-being and orientations to happiness. Journal of Religion and Health, 51, 934-946. https://doi.org/10.1007/s10943-010-9402-3

Berzin, A. (1988). Detachment, nonviolence and compassion. Retrieved from https://studybuddhism.com/ en/advanced-studies/science-of-mind/emotionalhygiene/detachment-nonviolence-and-compassion

Bretherton, I. (1992). The origins of attachment theory: John Bowlby and Mary Ainsworth. Developmental Psychology, 28, 759-775.

Caspi, A., Roberts, B. W., \& Shiner, R. L. (2005). Personality development: Stability and change. Annual Review of Psychology, 56, 453-484. https://doi. org/10.1146/annurev.psych.55.090902.141913

Chaplin, W. F. (2007). Moderator and mediator models in personality research: a basic introduction. In R. W. Robins, R. C. Fraley, \& R. F. Kreuger (Eds.), Handbook of research methods in personality psychology (pp. 602-362). New York, NY: Guilford Press.

Chen, Y. H. (2006). Coping with suffering: The Buddhist perspective. In P. T. P. Wong \& L. C. J. Wong (Eds.), Handbook of multicultural perspectives on stress and coping (pp. 73-89). Boston, MA: Springer.

Chio, F. H., Lai, M. H., \& Mak, W. W. (2018). Development of the Non-Attachment Scale - Short Form (NAS-SF) using item response theory. Mindfulness, 9, 1299-1308. https://doi.org/10.1007/s12671-017-0874-z

Culin, K. R. V., Tsukayama, E., \& Duckworth, A. L. (2014). Unpacking grit: Motivational correlates of perseverance and passion for long-term goals. The 
Journal of Positive Psychology, 9, 306-312. https:// doi.org/10.1080/17439760.2014.898320

Datu, J. A. D., Valdez, J. P. M., \& King, R. B. (2016). Perseverance counts but consistency does not! Validating the Short Grit Scale in a collectivist setting. Current Psychology, 35, 121-130. https://doi. org/10.1007/s12144-015-9374-2

Disabato, D. J., Goodman, F. R., \& Kashdan, T. B. (2018). Is grit relevant to well-being and strengths? Evidence across the globe for separating perseverance of effort and consistency of interests. Journal of Personality, 87, 194-211. https://doi.org/10.1111/ jopy.12382

Duckworth, A. L., \& Eskreis-Winkler, L. (2013). True grit. Observer, 26, 1-3.

Duckworth, A. L., \& Gross, J. J. (2014). Self-control and grit: Related but separable determinants of success. Current Directions in Psychological Science, 23, 319-325. https://doi.org/10.1177/0963721414541462

Duckworth, A. L., Peterson, C., Matthews, M. D., \& Kelly, D. R. (2007). Grit: Perseverance and passion for long-term goals. Journal of Personality and Social Psychology, 92, 1087-1101. https://doi. org/10.1037/0022-3514.92.6.1087

Duckworth, A. L., \& Quinn, P. D. (2009). Development and validation of the Short Grit Scale (Grit-S). Journal of Personality Assessment, 91, 166-174. https:// doi.org/10.1080/00223890802634290

Elphinstone, B., \& Whitehead, R. (2019). The benefits of being less fixated on self and stuff: Nonattachment, reduced insecurity, and reduced materialism. Personality and Individual Differences, 149, 302-308. https://doi.org/10.1016/j.paid.2019.06.019

Fischer-Schreiber, I., Ehrhard, F. K., Friedrichs, K., \& Diener, M. S. (1994). The encyclopedia of Eastern philosophy and religion: Buddhism, Taoism, Zen, Hinduism. Boston, MA: Shambhala.

Gillath, O., Karantzas, G. C., \& Lee, J. (2019). Attachment and social networks. Current Opinion in Psychology, 25, 21-25. https://doi.org/10.1016/j. copsyc.2018.02.010

Hadi, N. U., Abdullah, N., \& Sentosa, I. (2016). Making sense of mediating analysis: a marketing perspective. Review of Integrative Business \& Economics Research, 5, 62-76.

Hair Jr, J. F., Hult, G. T. M., Ringle, C., \& Sarstedt, M. (2016). A primer on partial least squares structural equation modeling (PLS-SEM). Thousand Oaks, CA: Sage Publications.

Henseler, J., Ringle, C. M., \& Sarstedt, M. (2015). A new criterion for assessing discriminant validity in variance-based structural equation modeling. Journal of the Academy of Marketing Science, 43, 115-135. https://doi.org/10.1007/s11747-014-0403-8

Kelly, B. D. (2008). Buddhist psychology, psychotherapy and the brain: a critical introduction. Transcultural Psychiatry, 45, 5-30. https://doi.org/ $10.1177 / 1363461507087996$
Khan, B. M., \& Khan, A. M. (2017). Grit, happiness and life satisfaction among professionals: a correlational study. Journal of Psychology and Cognition, 2, 123-132. https://doi.org/10.35841/psychology-cognition.2.2.123-132

Kleiman, E. M., Adams, L. M., Kashdan, T. B., \& Riskind, J. H. (2013). Gratitude and grit indirectly reduce risk of suicidal ideations by enhancing meaning in life: Evidence for a mediated moderation model. Journal of Research in Personality, 47, 539-546. https://doi.org/10.1016/j.jrp.2013.04.007

Lyubomirsky, S., \& Lepper, H. S. (1999). A measure of subjective happiness: Preliminary reliability and construct validation. Social Indicators Research, 46, 137-155. https://doi.org/10.1023/A:1006824100041

Nagar, I. (2018). Self-regulation for sustaining happiness and well-being: an Indian perspective. Psychological Studies, 63, 181-186. https://doi.org/10.1007/ s12646-017-0403-0

Pande, N. (2013). Kartavya: Understanding selfless acts. Psychology and Developing Societies, 25, 109132. https://doi.org/10.1177/0971333613477310

Pande, N., \& Tewari, S. (2011). Understanding coping with distress due to physical disability. Psychology and Developing Societies, 23, 177-209. https:// doi.org/10.1177/097133361102300203

Pandey, J., \& Singh, M. (2015). Asakti-Anasakti as mediator of emotional labor strategies and burnout: a study on ASHA workers. Indian Journal of Industrial Relations, 51, 57-68.

Park, N., Peterson, C., \& Seligman, M. E. (2004). Strengths of character and well-being. Journal of Social and Clinical Psychology, 23, 603-619. https:// doi.org/10.1521/jscp.23.5.603.50748

Peluso, P. R., Peluso, J. P., White, J. F., \& Kern, R. M. (2004). A comparison of attachment theory and individual psychology: a review of the literature. Journal of Counseling \& Development, 82, 139-145. https://doi.org/10.1002/j.1556-6678.2004.tb00295.x

Rimfeld, K., Kovas, Y., Dale, P. S., \& Plomin, R. (2016). True grit and genetics: Predicting academic achievement from personality. Journal of Personality and Social Psychology, 111, 780-789. https:// doi.org/10.1037/pspp0000089

Roberts, B. W., Luo, J., Briley, D. A., Chow, P. I., Su, R., \& Hill, P. L. (2017). A systematic review of personality trait change through intervention. Psychological Bulletin, 143, 117-141. https://doi.org/10.1037/ bul0000088

Sahdra, B., Ciarrochi, J., \& Parker, P. (2016). Nonattachment and mindfulness: Related but distinct constructs. Psychological Assessment, 28, 819-829. https://doi.org/10.1037/pas0000264

Sahdra, B., Ciarrochi, J., Parker, P. D., Marshall, S., \& Heaven, P. (2015). Empathy and nonattachment independently predict peer nominations of prosocial behavior of adolescents. Frontiers in Psychology, 6, 1-12. https://doi.org/10.3389/fpsyg.2015.00263 
Sahdra, B., \& Shaver, P. R. (2013). Comparing attachment theory and Buddhist psychology. International Journal for the Psychology of Religion, 23, 282293. https://doi.org/10.1080/10508619.2013.795821

Sahdra, B., Shaver, P. R., \& Brown, K. W. (2010). A scale to measure nonattachment: a Buddhist complement to Western research on attachment and adaptive functioning. Journal of Personality Assessment, 92, 116-127. https://doi.org/10.1080/00223890903425960

Sedlmeier, P., Losse, C., \& Quasten, L. C. (2018). Psychological effects of meditation for healthy practitioners: an update. Mindfulness, 9, 371-387. https://doi.org/10.1007/s12671-017-0780-4

Siah, P. C., Ng, A. H. W., Dharmaraj, E., Foo, C., Tan, S. M., \& Wider, W. (2019). Grit personality as a mediator or moderator for the effects of internet addiction on procrastination. Journal of Institutional Research South East Asia, 17, 18-32.

Siah, P. C., Ong, P. J. M., Ngiam, S. J., \& Tan, J. T. A. (2018). The mediating effect of grit on sleep quality and academic performance among undergraduates in Malaysia. Journal of Institutional Research South East Asia, 16, 112-125.

Specht, J., Egloff, B., \& Schmukle, S. C. (2011). Stability and change of personality across the life course: The impact of age and major life events on mean-level and rank-order stability of the Big Five. Journal of Personality and Social Psychology, 101, 862-882. https://doi.org/10.1037/a0024950

Trinh, L., \& Khanh, H. (2019). Happy people: Who are they? A pilot indigenous study on conceptualization of happiness in Vietnam. Health Psychology Report, 7, 296-304. https://doi.org/10.5114/ hpr.2019.88527

Upadhyay, R. P., \& Vashishtha, A. C. (2014). Effect of Anasakti and level of post on job satisfaction of employees. International Journal of Indian Psychology, 2, 101-107.

Vallerand, R. J. (2012). The role of passion in sustainable psychological well-being. Psychology of Well-Being: Theory, Research and Practice, 2, 1-21. https://doi.org/10.1186/2211-1522-2-1

Webster, J. D. (1998). Attachment styles, reminiscence functions and happiness in young and elderly adults. Journal of Aging Studies, 12, 315-330. https://doi.org/10.1016/S0890-4065(98)90006-8

Whitehead, R., Bates, G., \& Elphinstone, B. (2019). Growing by letting go: Nonattachment and mindfulness as qualities of advanced psychological development. Journal of Adult Development, 27, 12-22. https://doi.org/10.1007/s10804-018-09326-5

Zhao, X., Lynch Jr, J. G., \& Chen, Q. (2010). Reconsidering Baron and Kenny: Myths and truths about mediation analysis. Journal of Consumer Research, 37, 197-206. https://doi.org/10.1086/651257 